\title{
Uzun Kemik Osteomiyelitinin Nadir Bir Etkeni: Fusobacterium necrophorum
}

\section{An Uncommon Pathogen Causing Long Bone Osteomyelitis: Fusobacterium necrophorum}

\begin{abstract}
Özet
Osteomiyelite yol açan patojenler çeşitlilik göstermekle birlikte, bağışıklığı baskılanmış hastalarda daha nadir görülen mikroorganizmalar da etken olabilmektedir. Bu çalışmada nadir bir vaka olarak, Fusobacterium cinsi bir bakterinin sebep olduğu osteomiyelitten muzdarip bir hastanın tanı ve tedavisini sunmayı amaçladık.

48 yaşındaki kadın hasta sol uyluğunda üç aydır mevcut olan ağrı ve şişlik şikayetiyle bize başvurdu. Çekilmiş olan MR görüntülerine göre malign kemik tümörü ön tanısı alarak kliniğimize sevk edilmişti. Hastanın skleroderma nedeniyle immünosüpresif ilaç kullanma hikayesi mevcuttu. İlk başvurudan iki gün sonra patolojik femur kırığı geçiren hastaya osteomiyelitin cerrahi tedavisi olarak apse drenajı, debridman ve kırık için de antibiyotikli sement kaplı intramedüller çivi ile osteosentez ameliyatı yapıldı. Ameliyat öncesinde alınan örneklerin kültüründe Fusobacterium necrophorum üredi. Yatışı sırasında vakum yardımlı kapama ile takip edilen hasta, akut faz reaktanları normale döndükten ve IV antibiyotik tedavisi tamamlandıktan sonra taburcu edildi.

İmmün sistemi baskılanmış hastalarda Fusobacterium cinsi bakterilerin osteomiyelit etkeni olabileceği ve kemikteki litik lezyonların ayırıcı tanısında osteomiyelit olasılığı akılda tutulmalıdır.

Anahtar Kelimeler. Fusobacterium necrophorum; osteomiyelit; sement kaplı çivi
\end{abstract}

\section{Abstract}

Although pathogens causing osteomyelitis vary, relatively uncommon microorganisms can cause osteomyelitis in immunosuppressed patients. In this study we aimed to present the diagnosis and treatment of a patient with a rare case of osteomyelitis due to infection with a species of Fusobacterium.

A 48-year-old female patient complaining of swelling and pain in her left thigh for the last three months was referred to our clinic with a prediagnosis of bone malignancy based on the MRI findings. The patient had a history of immunosuppressive drug use for scleroderma. The patient suffered a pathological femoral fracture two days after her first visit to us. Abscess drainage and debridement were performed to treat her osteomyelitis, and an osteosynthesis including antibiotic cement-coated intramedullary nail insertion was performed for the fracture. Fusobacterium necrophorum grew in the culture of the preoperative specimens. The patient for whom vacuum-assisted closure was used during her hospitalization was discharged after the acute phase reactants returned to normal and the IV antibiotic treatment was completed. It should be noted that bacteria from the genus Fusobacterium can cause osteomyelitis in immunosuppressed patients, and that while making the differential diagnosis of the lytic lesions of bones osteomyelitis is one of the possibilities.

Key Words: Fusobacterium necrophorum; osteomyelitis; cement-coated nail
Ahmet Salduz, Necmettin Turgut, Serkan Bayram, Murat Altan, Mehmet Chodza, Mehmet Ekinci, Turgut Akgül

\section{İstanbul Üniversitesi}

İstanbul Tıp Fakültesi, Ortopedi ve Travmatoloji AD. İstanbul, Türkiye

Geliş Tarihi /Received : 07.11.2015 Kabul Tarihi /Accepted: 06.02.2015

Sorumlu Yazar/Corresponding Author Dr. Necmettin Turgut İstanbul Üniversitesi, İstanbul Tıp Fakültesi, Ortopedi ve Travmatoloji AD. Çapa, 34093, İstanbul/Türkiye

E-mail: drnecmettinturgut@hotmail.com 


\section{GíRiş}

Osteomiyelit yaşlanan toplumlarda giderek yaygınlaşan bir sağlık sorunudur. Tiptaki teknolojik gelişim ve ilerleyen farmakoloji sayesinde daha önce ölümcül seyreden osteomiyelit vakalarında mortalite azalmıştır. Osteomiyelit etkenleri arasında nadiren de olsa anaerobik gram-negatif basiller yer alabilmektedir (1). Tanıda gecikmeye yol açmamak için gerektiğinde kemik kültürü, yumuşak doku kültürü ve eklem aspirat örnekleri çok beklenmeden alınmalıdır (2).

Osteomiyelit kemiğe ait bir enfeksiyon olup enflamasyon belirtileriyle kendini göstermektedir. Osteomiyelite neden olabilecek birçok patojen bulunmaktadır. Bu olgu sunumumuzda osteomiyelitin nadir bir etkeni olarak karşımıza çıkan bir Fusobacterium türünü ve ona bağlı gelişen patolojik kırık ve tedavisini sunmayı amaçladık. Bağışıklığı baskılanmış hastalarda nadir görülen osteomiyelit patojenleri etiyolojide daha fazla akla getirilmeli ve de geçmeyen ağrı ve süren kilo kaybı gibi durumlarda malignitenin yanı sıra enfeksiyondan da kuşkulanılmalıdır.

\section{OLGU SUNUMU}

48 yaşındaki kadın hasta sol uyluğunda 3 aydır mevcut olan ağrı ve son bir ayda belirginleşen şişlik şikayetiyle kliniğimize yönlendirildi. Halsizliği, iştahsızlığı, gece terlemesi olan, son bir yıl içinde 30 kg kaybetmiş bulunan, ateşi olmayan hastanın yük verme ile sol uylukta ağrısı ve yürüme güçlüğü vardı.

Yapılan muayenede sol uylukta sağa göre bacak çapında artış olduğu, 1sı artışı ve kızarıklık olmadığı görüldü. Laboratuvar incelemelerinde CRP: $427 \mathrm{mg} / \mathrm{L}$, ESR: $122 \mathrm{~mm} / \mathrm{h}$, WBC: 9500/mm³, Hb: 7,9 g/dl, Hct: 24,3 olarak görülen hastada, akut faz reaktanları belirgin olarak yüksek saptandı. Çekilen direkt grafilerde sol femur medialinde kemiği destrükte eden, sınırları belirgin olmayan litik lezyon ve eşlik eden periost reaksiyonu izlendi (Resim 1). Dış merkezde çekilmiş olan MR görüntülerinde sol uyluk distal kesiminde diafizer yerleşimli, kortikal destrüksiyona yol açan, yumuşak dokuya uzanım gösteren $75^{\star} 125 \mathrm{~mm}$ boyutunda T2 sekansta hipointens septaları bulunan, kontrast tutulumu gösteren kitlesel lezyon olduğu yorumlandı. Femur medullasinda da T2 sekansinda hiperintens sinyal değişikliği mevcut olan lezyon, radyolog tarafından ön planda osteosarkom olarak yorumland (Resim 2).

Kesin tanıya ulaşmak için apse veya tümör komponenti olduğu düşünülen distal uyluk anteromedialindeki yumuşak dokudan tru-cut biyopsi yapıldı. Biyopsi sonucu gelmeden hasta 2 gün sonra patolojik kırık ile tarafımıza başvurdu (Resim 3). Servise yatırılan hastanın tetkikleri devam ederken alınan biyopsi sonucu, patoloji birimince nekrotizan iltihabi doku ile uyumlu olarak değerlendirildi. Osteomiyelit, apse formasyonu ve patolojik kırığa yönelik olarak operasyon planlandı.

\section{CERRAHI TEKNIK}

Genel anestezi altında hasta supin pozisyonda hazırlandıktan sonra distal uyluk anteromedialinden yaklaşı $10 \mathrm{~cm}$ insizyon ile girildi. Cilt altından itibaren kahverengi nekrotik karakterli, pürülan, yüksek basinçlı ve kötü kokulu 3 lt apse materyali drene edildi; nekrotik kemik fragmanları çıkarıldı. Gram boyama, kültür-antibiyogram ve patoloji örnekleri alındı. $10.000 \mathrm{cc} \% 0,9 \mathrm{NaCl}$ izotonik sıvı ile yıkandı. Povidon iodin emdirilmiş gazlar ile osteomiyelit sahası $10 \mathrm{da}$ kika süreyle yüksek doz iyot ile sterilize edildi. Kırık tespiti, üzerine antibiyotikli sement yerleştirilmiş trokanterik girişli LFN (Synthes) çivisi ile yapıldı. $800 \mathrm{mg}$ teikoplanin karıştırılmış sement toraks tüpü ile şekil verilerek çivi üzerine yerleştirildi. Uyluk medialinden apse boşaltılan bölgede yine $800 \mathrm{mg}$ teikoplanin ve sement ile hazırlanan antibiyotikli boncuk uygulaması ile operasyon tamamlandı (Resim 4). Vakum yardıml kapama (vacuum-assisted closure-VAC) süngerleri ile aralıksız drenaj yapılarak eksüda dışarı alınmaya çalışıldı.

\section{TAKIP}

Enfeksiyon Hastalıkları birimince postoperatif dönemde ampirik antibiyoterapi olarak sefazolin $4^{\star} 2$ gr IV ve günde bir adet rifampisin $300 \mathrm{mg}$ tb başlandı. Alınan preoperatif örnekler için öncelikle gram boyama işlemi gerçekleştirildi. Etkenin gram-negatif çomak olduğu görüldü. Aerobik kültür için 24 saat ve anaerobik kültür için 48 saat süre ve ayrı ayrı Petri kapları kullanıldı. Altı disk yöntemi ve dörtlü antibiyotik (AMC, metronidazol, meropenem, imipenem) kullanıldı. ASM/CLSI kılavuzu kullanılarak etkenin 


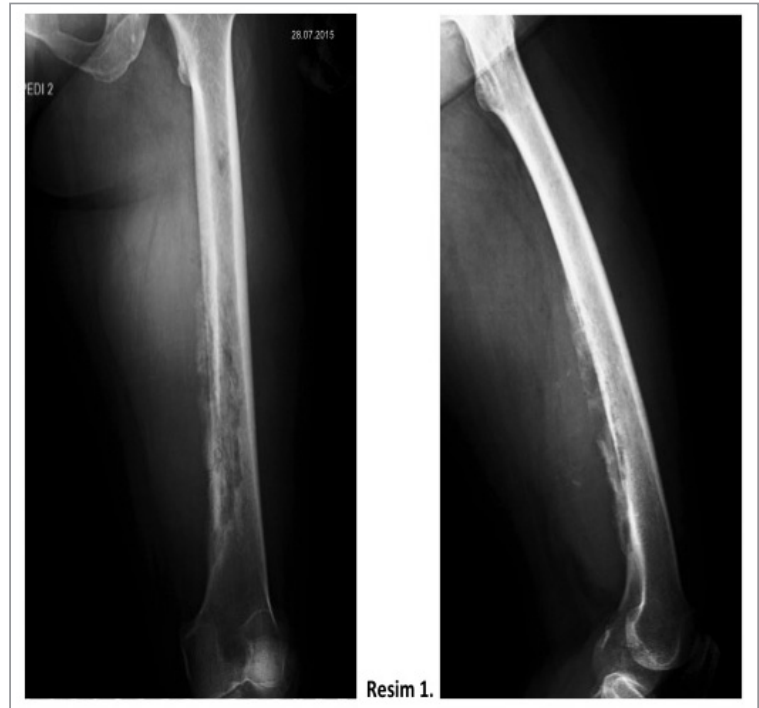

Resim 1. Hastanın ilk başvurusundaki sol femur AP ve lateral grafileri. Femur medialindeki litik alan, periost reaksiyonu ve apseye bağlı yumuşak doku gölgesi dikkat çekmektedir.

Fusobacterium cinsine ait bir bakteri olduğu belirlendi. Ticari API kiti ile Fusobacterium necrophorum olduğu belirlendi. Postoperatif dördüncü günde Enfeksiyon Hastalıkları birimince hastanın antibiyoterapisi değiştirildi ve $4^{\star} 2$ gr ampisilin-sulbaktam ve $3^{\star} 500$ mg metronidazol tedavisine başlandı. Hastanede yattığı sürede VAC pansuman ile takip edilen hastanın enfeksiyon belirteçleri normale gelinceye kadar 6 hafta boyunca antibiyoterapisine devam edildi. Taburculuk öncesi VAC pansuman bölgesinden yaklaşılarak antibiyotikli zincirler çıkarıldı ve yara sütüre edilerek kapatıldı. Akıntısı olmayan ve genel durumu iyi olan hasta oral antibiyoterapi ile taburcu edildi (Resim 5).

\section{TARTIŞMA}

Osteomiyelit kemikte çoğalan patojenik mikroorganizmaların neden olduğu bir iltihap olarak tanımlanabilir. Osteomiyelite neden olabilecek birçok bakteriyel, fungal, viral etiyolojik ajan bulunmaktadır. Anaerobik bakterilerin yol açtığı osteomiyelit ise daha nadir görülmektedir. Tanısal çalışmaların gelişmesiyle beraber anaerobik bakterilerin kültürde üretilme ihtimali artmıştır. Buna bağlı olarak da anaerobik enfeksiyonların diğerlerine oranında kayda değer bir artış göze çarpmaktadır. Osteomiyelite yol açabilecek anaerobik bakteriler arasinda Peptostreptococcus, Bacteroides ve Clostridium türleri, cilt florasından Propionibacterium acnes ve Fusobacterium türleri sayllabilir. Fusobacterium türlerinden kaynaklanan osteomiyelitler literatürde ancak vaka raporları şeklinde bildirilmiş olup geniş vaka serilerine dayanan araştırmalar ne yazık ki mevcut değildir.

Fusobacterium cinsi bakteriler; anaerobik, sporsuz, gram-negatif basillerdir (3). Bu cinsten Fusobacterium nucleatum ve Fusobacterium necrophorum en sik izole

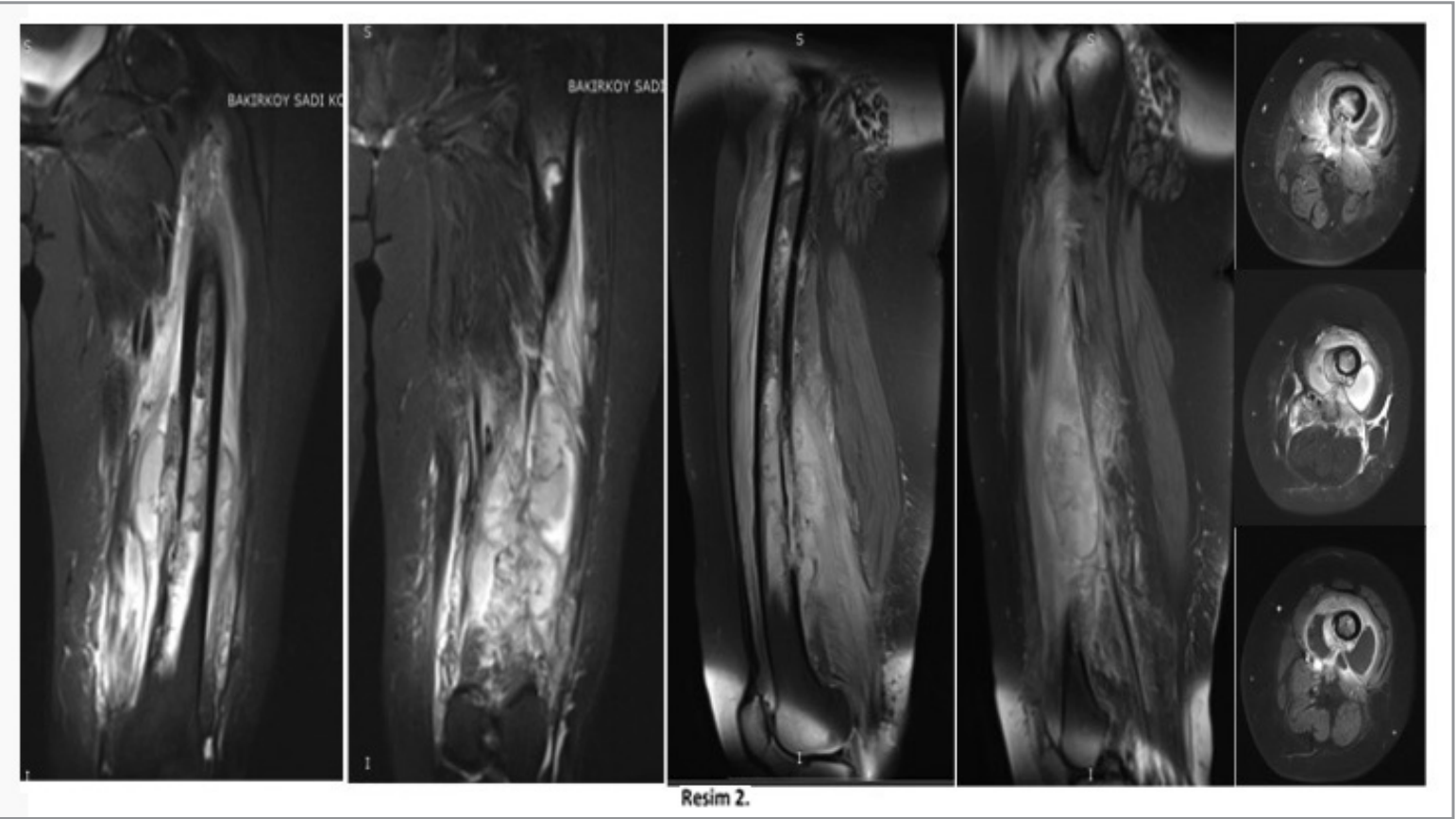

Resim 2. Hastanın ilk başvurudaki MR görüntüleri. 
edilen iki patojendir $(4,5)$. Fusobacterium türleri normal sağlıklı bireylerde orofarengeal bölgede bulunup diş plaklarında komponent olarak yer alırlar (3). Bunun dışında doğal olarak ürogenital traktusta, gastrointestinal traktusta ve vajinal mukozada da bulunurlar. Literatürde hemen her vücut bölgesinde Fusobacterium türlerinden ileri gelen enfeksiyonlar bildirildiği görülmektedir (6). En bilinen tablo, Fusobacterium necrophorum türünün neden olduğu Lemierre sendromudur. Lemierre sendromu; internal juguler vende süpüratif tromboflebit, septik emboli, multipl organ disfonksiyonu, menenjit, venöz sinüs trombozu, artrit, osteomiyelit ile kendini gösteren bir sendromdur (7). Literatürde şimdiye kadar 16 hastada da Fusobacterium etkenli spondilodiskit rapor edilmiştir (8). Fusobacterium türleri daha çok oral flora bakterisi olmalarının da etkisiyle kraniyal ve fasiyal enfeksiyonlara neden olmaktadirlar (9).

Fusobacterium etkenli osteomiyelit, açı temastan ziyade hematojen yolla gerçekleşmekte ve de çocuklarda ve bağışıklığı zayıf hastalarda meydana gelmektedir. Hematojen yolla oral enfeksiyonlar, diş apseleri vb. durumlar sonrasında enfeksiyonlar geliştiğine dair yayınlar mevcuttur. Dolayısıyla klinisyen olarak Fusobacterium etkenli osteomiyelitin başka bir enfeksiyonun sonucunda gelişmiş olabileceğini de hesaba katmamız gerekmektedir. Fusobacterium etkenli osteomiyelit tanısı konduğunda, bakteriyemiye yol açan kaynak olarak üst solunum yollarında, sindirim sisteminde, oral-kraniyal bölgede başkaca enfeksiyonların olup olmadığı araştırılmalıdır. Bizim hastamızda sistemik skleroz nedeniyle uzun süre immünosüpresif ilaç (metotreksat, metilprednizolon) kullanılmış olmasının fırsatçı anaerobik enfeksiyonların gelişimini kolaylaştırdığı düşünüldü. Daha önce yapılmış olan kolonoskopisinde rektal bölgede darlık olduğu belirtilmiş ve PET raporlarına göre kapalı bağırsak perforasyonu geçirmiş olan hastanın gastrointestinal sistemden hematojen yolla enfekte olduğunu düşünmekteyiz.

Osteomiyelit, tedavisi hala oldukça güç bir hastalıktır. Birçok tedaviyi kombine etmek gerekebilir. Enfeksiyonun kronikleşmemesi için ampirik antibiyoterapi derhal başlamalıdır. Tedavi için yapılacaklar; hastanın değerlendirilmesini, evrelendirilmesini, mikrobiyal etiyoloji ve antibiyotik duyarlılıkların belirlenmesini takiben, antimikrobiyal tedavi ve gerekliyse

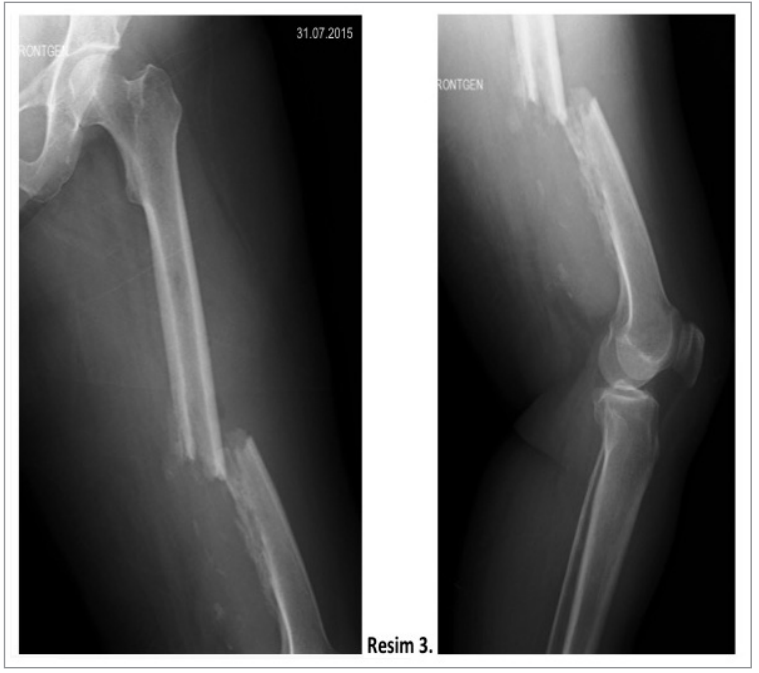

Resim 3. İlk başvurudan iki gün sonra meydana gelen sol femur patolojik kırık röntgenleri.

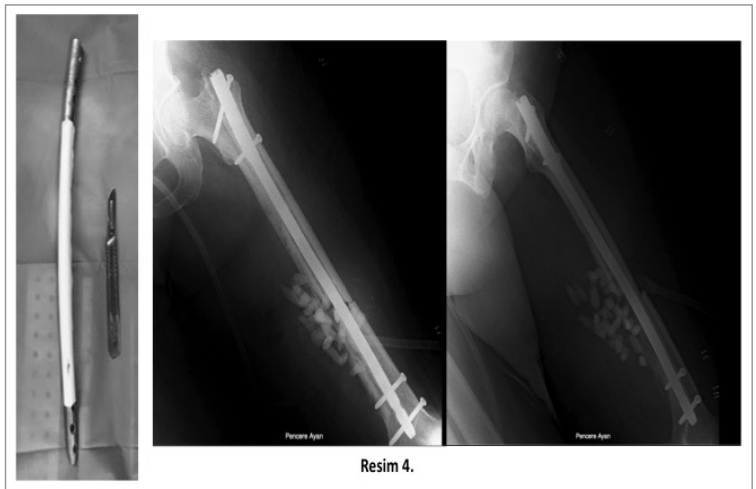

Resim 4. Hastaya yerleştirilen el yapımı antibiyotikli IM çivi ve erken postoperatif femur AP ve lateral grafileri.

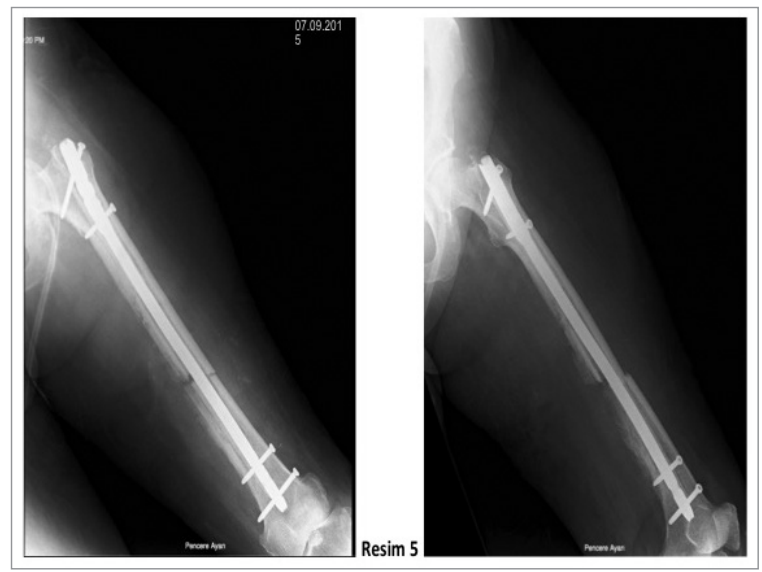

Resim 5. Hastanın ameliyat sonrası 6. haftada çekilen grafileri. 
debridman, ölü boşluk yönetimi ve kemiğin stabilizasyonu olarak sıralanabilir (10).

Osteomiyelitin hayat konforunu etkileyen birçok komplikasyonu bulunmaktadır. En önemli komplikasyonları arasında sepsis, skuamöz hücreli karsinom gelişimi, ampütasyon, lizise bağlı olarak kırık oluşumu sayılabilir. Bizim hastamızda şiddetli bir travma, düşme vb. bir olay olmaksızın ev içinde yürürken patolojik kırık gerçekleşmiştir. Patolojik kırıklara malignite, kemik kalitesinde azalma ya da enfeksiyon neden olabilir. Kemik yıkımının kemik yapımı ile dengelenememesi kırık oluşumuna katkıda bulunur.

Enfekte patolojik uzun kemik kırıklarının tedavisinde, apse drenajı ve debridman sonrası kırık tespiti için eksternal fiksatör veya antibiyotikli çivi ile osteosentez yöntemleri kullanılmaktadır. Son yıllarda osteomiyelit ve enfekte psödoartroz vakalarında tedavide güncel bir yaklaşım olarak antibiyotik kaplı çivi kullanımı popüler hale gelmiştir. Bilindiği gibi, lokal antibiyotik uygulamalarında enfeksiyon bölgesinde intravenöz yolla elde edilebilecek olan seviyeden 200 kat kadar daha yoğun bir antibiyotik konsantrasyonuna ulaşılabilmekte ve antibiyotik etki uygulama anından itibaren 4-6 hafta kadar sürmektedir. Çivinin kendisi yabancı bir cisim olmasına rağmen elde edilen sonuçlar yüz güldürücü olmuştur (11-13). Biz de tespit yöntemi olarak, osteomiyelit sinıflaması, hasta uyumu ve komorbiditeleri de dikkate alarak antibiyotikli intramedüller çivi ile osteosentez ameliyatını tercih ettik. Cerrahiye ek olarak lokal ve sistemik antibiyoterapiyi kombine ettiğimiz tedavi sonucunda hastanın şikayetleri geriledi, akut faz reaktanları normal değerlerine döndü. İmplant ilişkili enfeksiyon belirtisine rastlanmadi.

Fusobacterium türleri; penisilin-G, klindamisin, metronidazol, kloramfenikol, imipenem, sefoksitin içeren antimikrobiyallere karşı genellikle duyarlıdır (14). Fusobacterium türlerinin beta-laktamaz enzim üretimi nedeniyle beta-laktam grubu antibiyotiklere karşı direnç gelişimi söz konusudur. Hastamızda öncelikle ampirik antibiyoterapi başlanmış olup kültürde Fusobacterium cinsi bakteri izole edilince beta-laktam-beta-laktamaz inhibitörü olarak $4^{\star} 2$ gr ampisilin-sulbaktam ve $3^{\star} 500 \mathrm{mg}$ metronidazol tedavisi başlanmış, altı hafta IV tedavi uygulanmıştır. Cerrahi ve antibiyoterapiye yanıt; akut faz reaktanları, yara yeri durumu, vital takipleri ile değerlendirilmiştir. Enfeksiyon Hastalıkları birimince 6. hafta sonunda oral antibiyoterapiye geçilmesi önerilmesi sonucunda hasta taburcu edilmiştir.

\section{SONUÇ}

Bağışılklı̆̆ baskılanmış hastalarda Fusobacterium türleri gibi anaerobik fırsatçı bakteriler de osteomiyelit etkeni olabilmektedir. Erken tanı ve uygun tedavi bu tür hastalarda morbidite ve mortaliteyi azaltmaya yardımcı olabilir. Kemikte litik lezyon ve kitle imajı ile gelen hastalarda ayırıcı tanıda neoplastik oluşumların yanı sıra osteomiyelit olasılığı da akıldan çıarılmamalıdır. Bizim bildiğimiz kadarıyla hastamız, Fusobacterium etkenli osteomiyelitlerde bildirilen ilk patolojik kırık vakasıdır.

\section{KAYNAKLAR}

1. Lewis RP, Sutter VL, Finegold SM. Bone infections involving anaerobic bacteria. Medicine. 1978;57(4):279305.

2. Hatzenbuehler J, Pulling TJ. Diagnosis and management of osteomyelitis. Am Fam Physician. 2011;84(9):102733.

3. Bolstad AI, Jensen HB, Bakken V. Taxonomy, biology, and periodontal aspects of Fusobacterium nucleatum. Clin Microbiol Rev. 1996;9(1):55-71.

4. Huggan PJ, Murdoch DR. Fusobacterial infections: clinical spectrum and incidence of invasive disease. J Infect. 2008;57(4):283-9.

5. Goldberg EA, Venkat-Ramani T, Hewit M, Bonilla HF. Epidemiology and clinical outcomes of patients with Fusobacterium bacteraemia. Epidemiol Infect. 2013;141(2):325-9.

6. Citron DM. Update on the taxonomy and clinical aspects of the genus fusobacterium. Clin Infect Dis. 2002;35(Suppl 1):S22-7.

7. Creemers-Schild D, Gronthoud F, Spanjaard L, Visser LG, Brouwer CNM, Kuijper EJ. Fusobacterium necrophorum, an emerging pathogen of otogenic and paranasal infections? New Microbes New Infect. 2014;2(3):52-7.

8. Latta TN, Mandapat AL, Myers JP. Anaerobic spondylodiscitis due to Fusobacterium Species: a case report review of the literature. Case Rep Infect Dis. 2015;2015:759539.

9. Le Monnier A, Jamet A, Carbonnelle E, Barthod G, Moumile K, Lesage F, et al. Fusobacterium necrophorum middle ear infections in children and related com- 
plications: report of 25 cases and literature review. Pediatr Infect Dis J 2008;27(7):613-7.

10. Carek PJ, Dickerson LM, Sack JL. Diagnosis and management of osteomyelitis. Am Fam Physician. 2001;63(12):2413-20 (Erratum: Am Fam Physician 2002;65(9):1751).

11. Thonse R, Conway JD. Antibiotic cement-coated nails for the treatment of infected nonunions and segmental bone defects. J Bone Joint Surg Am. 2008;90 (Suppl 4):163-74.

12. Chou DT, Pullinger M, Davis B. A method of fabricating an antibiotic cement spacer using an elastic nail for the treatment of intramedullary osteomyelitis.Ann R Coll Surg Engl. 2015;97(2):157-8.
13. Nizegorodcew T, Palmieri G, Marzetti E. Antibioticcoated nails in orthopedic and trauma surgery: state of the art. Int J Immunopathol Pharmacol. 2011;24(1 Suppl 2):125-8.

14. Brook I. Microbiology and management of joint and bone infections due to anaerobic bacteria. J Orthop Sci. 2008;13(2):160-9. 